
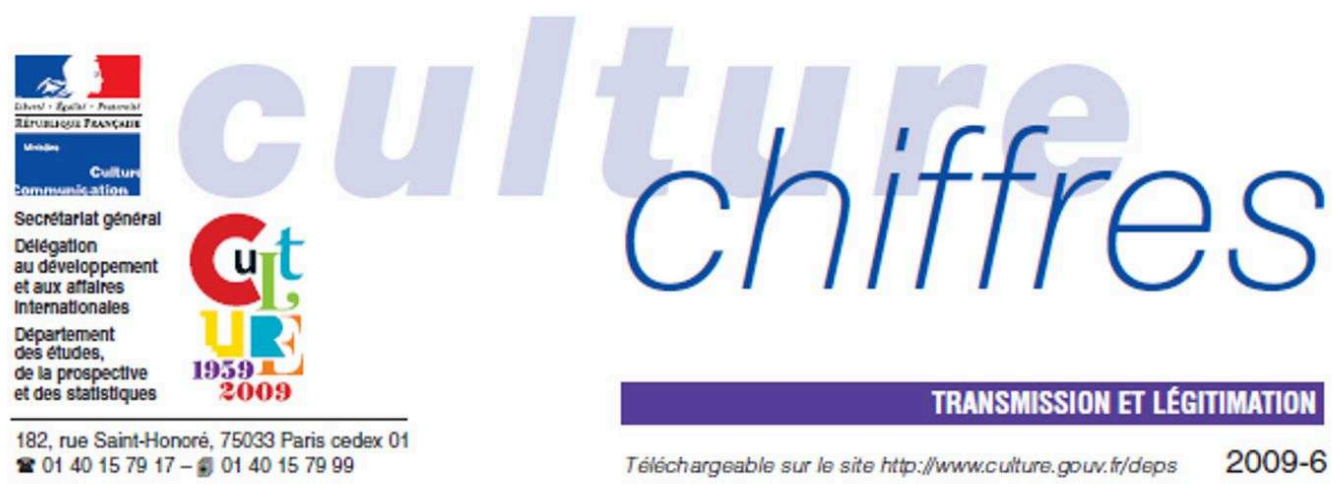

\title{
Les établissements d'enseignement supérieur artistique et culturel relevant du ministère de la Culture et de la Communication Année scolaire 2008-2009
}

\author{
Edwige Zadora*
}

L'enseignement supérieur artistique et culturel en France se caractérise par une grande diversité institutionnelle. Il relève d'établissements publics et privés de taille et de statut très variés. Certains d'entre eux sont des établissements publics à vocation nationale sous tutelle du ministère de la Culture et de la Communication, d'autres dépendent des ministères chargés de l'Éducation nationale et de l'Enseignement supérieur, d'autres encore sont des établissements gérés par des collectivités territoriales. Dans certains domaines, tels que l'archéologie ou la gestion et médiation culturelles par exemple, les formations sont essentiellement assurées par les universités. Enfin, un large éventail de formations préparant aux différents métiers de la culture est proposé par de nombreuses écoles du secteur privé. Les données présentées concernent les établissements d'enseignement supérieur artistique et culturel relevant du ministère de la Culture et de la Communication qui dispensent des formations initiales.

\section{3 écoles}

La formation initiale supérieure artistique et culturelle relevant du ministère de la Culture et de la Communication est assurée dans 123 établissements ${ }^{1}$ et porte sur les domaines suivants:

- arts plastiques (58 établissements);

- spectacle vivant ${ }^{2}$ (40 établissements);

- architecture et paysage (21 établissements);

- patrimoine (2 établissements) ;

- cinéma et audiovisuel (2 établissements).

* Chargée d'études au ners:

1. Pour la liste complète de ces écoles, voir l'annexe en page 4

2. Musique, danse, théstre, cirque, marionnette.
Ces établissements sont soit placés sous tutelle ou contrôle pédagogique du ministère de la Culture et de la Communication, soit reçoivent une subvention publique de l'État.

\section{0 élèves}

En 2008-2009, les établissements d'enseignement supérieur artistique et culturel relevant du ministère de la Culture ont accueilli plus de 33500 élèves (tableau 1). Plus de la moitié d'entre eux sont inscrits dans les écoles d'ar-

Tableau 1 - Répartition des élèves par domaine et par sexe (année scolaire 2008-2009)

\begin{tabular}{|c|c|c|c|}
\hline \multirow[b]{2}{*}{ Domaines } & mbre d'elèves & \multicolumn{2}{|c|}{ dont } \\
\hline & & femmes & hommes \\
\hline Architecture ot paysage 1 & 17599 & 55 & 45 \\
\hline Arts plastiques ${ }^{2}$ & 10240 & 64 & 36 \\
\hline Spectacle vivant & 3832 & 53 & 47 \\
\hline dont Celederm ot $\operatorname{cess}^{4}$ & 730 & 63 & 37 \\
\hline ot OFM & 339 & 65 & 35 \\
\hline Patrimoine & 1632 & 80 & 20 \\
\hline Cinema et audiovisuel & 251 & 50 & 50 \\
\hline Total & 33554 & 59 & 41 \\
\hline \multicolumn{4}{|c|}{ 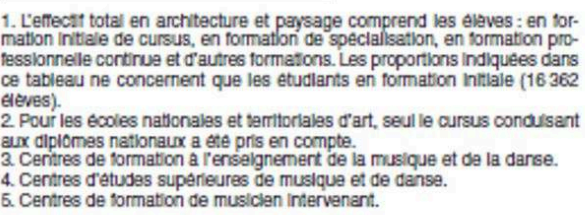 } \\
\hline
\end{tabular}




\section{Les établissements d'enseignement supérieur artistique et culturel relevant du ministère de la Culture et de la Communication}

Année scolaire 2008-2009

Edwige Zadora

Éditeur : Département des études, de la prospective et des statistiques

Lieu d'édition : Paris

Année d'édition : 2009

Date de mise en ligne : 21 septembre 2015

Collection : Culture chiffres

ISBN électronique : 9782111398474

\section{Sbooks}

http://books.openedition.org

\section{Édition imprimée}

Date de publication : 1 décembre 2009

Nombre de pages : 4

\section{Référence électronique}

ZADORA, Edwige. Les établissements d'enseignement supérieur artistique et culturel relevant du ministère de la Culture et de la Communication: Année scolaire 2008-2009. Nouvelle édition [en ligne]. Paris :

Département des études, de la prospective et des statistiques, 2009 (généré le 25 avril 2021)

Disponible sur Internet : <http://books.openedition.org/deps/570>. ISBN : 9782111398474. 


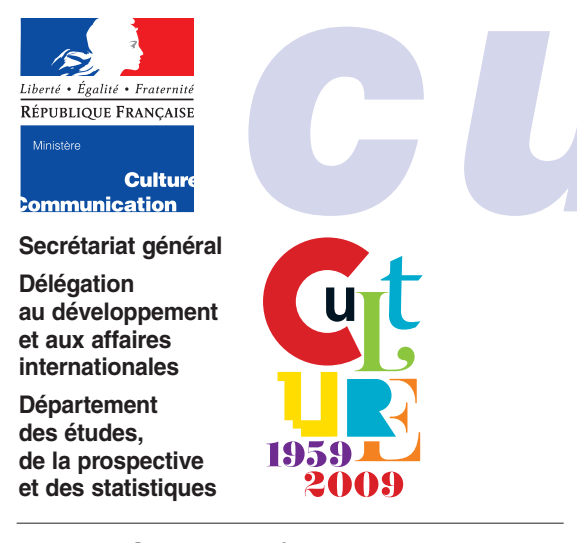

182, rue Saint-Honoré, 75033 Paris cedex 01 面 0140157917 - 睓 0140157999

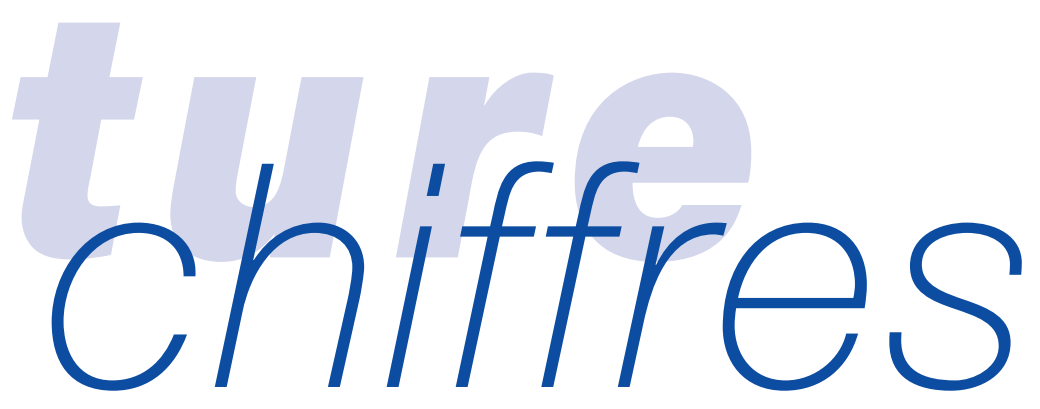

TRANSMISSION ET LÉGITIMATION

\title{
Les établissements d'enseignement supérieur artistique et culturel relevant du ministère de la Culture et de la Communication Année scolaire 2008-2009
}

\author{
Edwige Zadora*
}

L'enseignement supérieur artistique et culturel en France se caractérise par une grande diversité institutionnelle. Il relève d'établissements publics et privés de taille et de statut très variés. Certains d'entre eux sont des établissements publics à vocation nationale sous tutelle du ministère de la Culture et de la Communication, d'autres dépendent des ministères chargés de l'Éducation nationale et de l'Enseignement supérieur, d'autres encore sont des établissements gérés par des collectivités territoriales. Dans certains domaines, tels que l'archéologie ou la gestion et médiation culturelles par exemple, les formations sont essentiellement assurées par les universités. Enfin, un large éventail de formations préparant aux différents métiers de la culture est proposé par de nombreuses écoles du secteur privé. Les données présentées concernent les établissements d'enseignement supérieur artistique et culturel relevant du ministère de la Culture et de la Communication qui dispensent des formations initiales.

\section{3 écoles}

La formation initiale supérieure artistique et culturelle relevant du ministère de la Culture et de la Communication est assurée dans 123 établissements ${ }^{1}$ et porte sur les domaines suivants :

- arts plastiques (58 établissements);

- spectacle vivant ${ }^{2}$ (40 établissements);

- architecture et paysage (21 établissements);

- patrimoine (2 établissements);

- cinéma et audiovisuel (2 établissements).

* Chargée d'études au DEPS.

1. Pour la liste complète de ces écoles, voir l'annexe en page 4.

2. Musique, danse, théâtre, cirque, marionnette.
Ces établissements sont soit placés sous tutelle ou contrôle pédagogique du ministère de la Culture et de la Communication, soit reçoivent une subvention publique de l'État.

\section{0 élèves}

En 2008-2009, les établissements d'enseignement supérieur artistique et culturel relevant du ministère de la Culture ont accueilli plus de 33500 élèves (tableau 1). Plus de la moitié d'entre eux sont inscrits dans les écoles d'ar-

\section{Tableau 1 - Répartition des élèves par domaine} et par sexe (année scolaire 2008-2009)

\begin{tabular}{|c|c|c|c|}
\hline \multirow[b]{2}{*}{ Domaines } & \multirow[t]{2}{*}{ mbre d'élèves } & \multicolumn{2}{|c|}{ dont } \\
\hline & & femmes & hommes \\
\hline Architecture et paysage ${ }^{1}$ & 17599 & 55 & 45 \\
\hline Arts plastiques $^{2}$ & 10240 & 64 & 36 \\
\hline Spectacle vivant & 3832 & 53 & 47 \\
\hline dont Cefedem ${ }^{3}$ et CESMD ${ }^{4}$ & 730 & 63 & 37 \\
\hline et CFMP & 339 & 65 & 35 \\
\hline Patrimoine & 1632 & 80 & 20 \\
\hline Cinéma et audiovisuel & 251 & 50 & 50 \\
\hline Total & 33554 & 59 & 41 \\
\hline \multicolumn{4}{|c|}{$\begin{array}{l}\text { 1. L'effectif total en architecture et paysage comprend les élèves : en for- } \\
\text { mation initiale de cursus, en formation de spécialisation, en formation pro- } \\
\text { fessionnelle continue et d'autres formations. Les proportions indiquées dans } \\
\text { ce tableau ne concernent que les étudiants en formation initiale (16 } 362 \\
\text { élèves). } \\
\text { 2. Pour les écoles nationales et territoriales d'art, seul le cursus conduisant } \\
\text { aux diplômes nationaux a été pris en compte. } \\
\text { 3. Centres de formation à l'enseignement de la musique et de la danse. } \\
\text { 4. Centres d'études supérieures de musique et de danse. } \\
\text { 5. Centres de formation de musicien intervenant. }\end{array}$} \\
\hline
\end{tabular}

Source : DEPS, Ministère de la Culture et de la Communication/ Ministère de l'Enseignement supérieur et de la Recherche, 2009 
chitecture et de paysage et près d'un tiers suivent des formations d'arts plastiques (graphique 1).

Les formations artistiques et culturelles sont suivies en majorité par des femmes, qui représentent $59 \%$ de l'effectif total (graphique 2).

Comme chaque année, on note des différences significatives selon les domaines artistiques : les femmes prédominent largement dans les formations patrimoniales $(80 \%)$

\section{Graphique 1 - Répartition des élèves par domaine (année scolaire 2008-2009)}

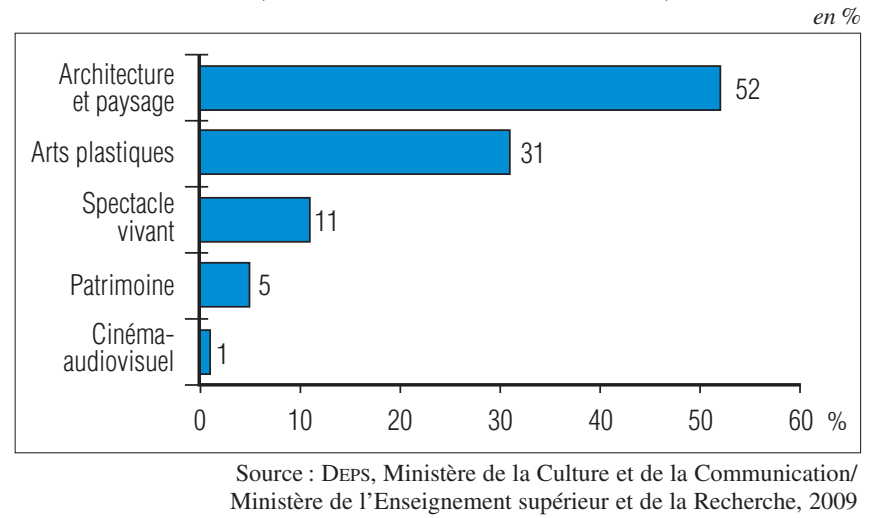

\section{Graphique 2 - Répartition des élèves par domaine} et par sexe (année scolaire 2008-2009)

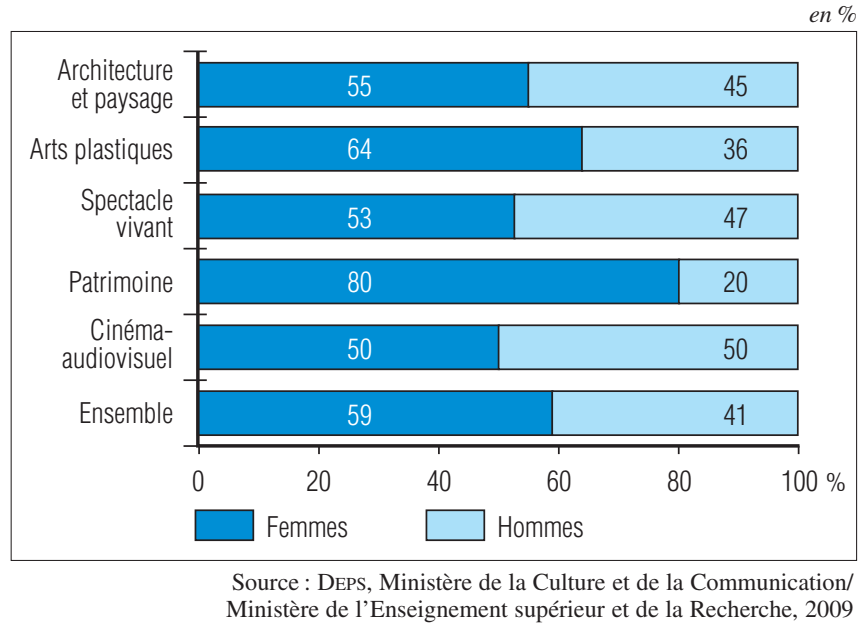

\section{Tableau 2 - Répartition des élèves par domaine} et par origine (année scolaire 2008-2009)

\begin{tabular}{|c|c|c|c|}
\hline Domaine & Total & Français & Étrangers \\
\hline Architecture et paysage ${ }^{1}$ & 17599 & 86 & 14 \\
\hline Arts plastiques & 10240 & 88 & 12 \\
\hline Spectacle vivant & 3832 & 88 & 12 \\
\hline Patrimoine & 1632 & 94 & 6 \\
\hline Cinéma et audiovisuel & 251 & 93 & 7 \\
\hline Total & 33564 & 87 & 13 \\
\hline \multicolumn{4}{|c|}{$\begin{array}{l}\text { 1. Les proportions indiquées ne concernent que les élèves en formation initiale de cur- } \\
\text { sus (16362 élèves). }\end{array}$} \\
\hline
\end{tabular}

et en arts plastiques (64\%). Elles sont également majoritaires dans les écoles d'architecture et de paysage (55\%) et celles du spectacle vivant $(53 \%)$, tandis que les écoles de cinéma et de l'audiovisuel accueillent autant d'hommes que de femmes.

Mis en place en 1998, un dispositif gouvernemental destiné à améliorer l'attractivité de la France pour les étudiants et chercheurs étrangers facilite l'accueil des étudiants dans les établissements supérieurs, y compris dans les disciplines artistiques. En 2008-2009, sur l'ensemble des formations, les étudiants étrangers représentent $13 \%$ des effectifs (tableau 2). Ils sont proportionnellement les moins nombreux dans les écoles du patrimoine $(6 \%)$ et de l'audiovisuel ( $7 \%$ ) et s'inscrivent, pour plus de la moitié d'entre eux, dans les écoles supérieures d'architecture.

\section{Une couverture territoriale inégale}

Les établissements d'enseignement artistique et culturel relevant du ministère de la Culture et de la Communication couvrent l'ensemble du territoire français à l'exception de la Corse, la Guyane et la Guadeloupe, qui ne disposent d'aucune école de ce type (tableau 3 et carte).

Dans le domaine des arts plastiques, chaque région (à l'exception des trois citées précédemment) dispose d'au moins une école, alors que les formations aux métiers de cinéma et de l'audiovisuel, les plus rares sur le territoire ne sont proposées qu'en Île-de-France. Dans le domaine du patrimoine, bien que les deux écoles d'enseignement spécifique soient implantées en région parisienne, des formations préparant aux métiers de conservateur-restaurateur des œuvres d'art sont également dispensées dans deux écoles territoriales d' $\mathrm{art}^{3}$.

Les trois régions les plus riches et les plus équipées en termes d'infrastructures culturelles - Île-de-France, Provence-Alpes-Côte d'Azur et Rhône-Alpes - concentrent à elles seules $56 \%$ des élèves et $40 \%$ des établissements.

\section{Carte - Effectif d'élèves dans les établissements d'enseignement supérieur artistique et culturel par région (année scolaire 2008-2009)}

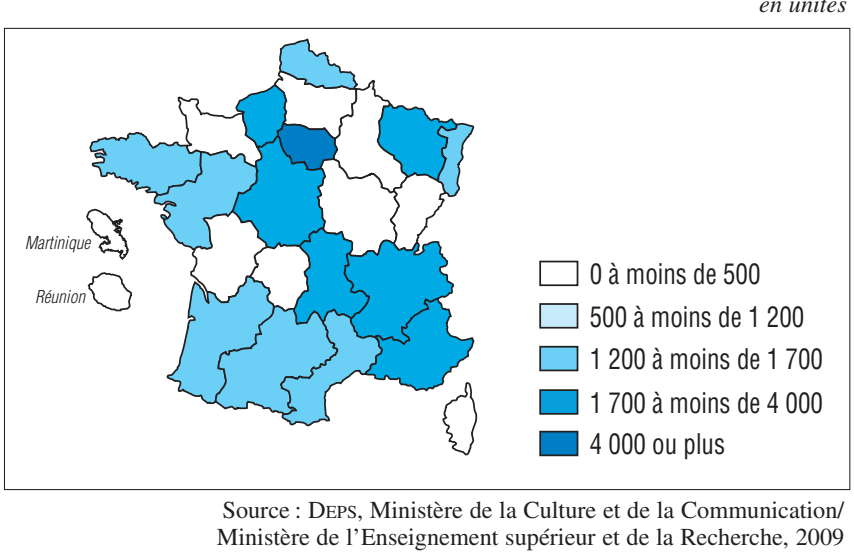

3. DNAP et DNSEP conservation-restauration des œuvres sculptées à Tours et DNAP et DNSEP conservation-restauration des œuvres peintes à Avignon. 
Tableau 3 - Répartition des élèves par région et par domaine (année scolaire 2008-2009)

\begin{tabular}{|c|c|c|c|c|c|c|c|}
\hline Région & $\begin{array}{l}\text { Nombre } \\
\text { d'écoles }\end{array}$ & $\begin{array}{c}\text { Effectif } \\
\text { total }\end{array}$ & Arts plastiques & $\begin{array}{l}\text { Spectacle } \\
\text { vivant }\end{array}$ & $\begin{array}{l}\text { Architecture } \\
\text { et paysage }\end{array}$ & Patrimoine & $\begin{array}{c}\text { Cinéma } \\
\text { et audiovisuel }\end{array}$ \\
\hline Île-de-France & 24 & 12729 & 1656 & 1872 & 7318 & 1632 & 251 \\
\hline Rhône-Alpes & 12 & 3936 & 1039 & 714 & 2183 & - & - \\
\hline Provence-Alpes-Côte d'Azur & 12 & 2325 & 1027 & 297 & 1001 & - & - \\
\hline Bretagne & 7 & 1459 & 794 & 55 & 610 & - & - \\
\hline Pays de la Loire & 6 & 1487 & 602 & 126 & 759 & - & - \\
\hline Alsace & 5 & 1384 & 614 & 71 & 699 & - & - \\
\hline Languedoc-Roussillon & 5 & 1367 & 333 & 12 & 1022 & - & - \\
\hline Nord - Pas-de-Calais & 9 & 1280 & 488 & 95 & 697 & - & - \\
\hline Aquitaine & 6 & 1297 & 326 & 79 & 892 & - & - \\
\hline Midi-Pyrénées & 5 & 1217 & 378 & 145 & 694 & - & - \\
\hline Lorraine & 5 & 1153 & 450 & 38 & 665 & - & - \\
\hline Haute-Normandie & 4 & 945 & 314 & 68 & 563 & - & - \\
\hline Auvergne & 2 & 655 & 159 & - & 496 & - & - \\
\hline Centre & 4 & 591 & 559 & 32 & - & - & - \\
\hline Poitou-Charentes & 3 & 338 & 241 & 97 & - & - & - \\
\hline Bourgogne & 3 & 299 & 244 & 55 & - & - & - \\
\hline Champagne-Ardenne & 2 & 211 & 159 & 52 & - & - & - \\
\hline Picardie & 2 & 162 & 147 & 15 & - & - & - \\
\hline Limousin & 2 & 137 & 128 & 9 & - & - & - \\
\hline Basse-Normandie & 2 & 246 & 246 & - & - & - & - \\
\hline Franche-Comté & 1 & 150 & 150 & - & - & - & - \\
\hline Réunion & 1 & 120 & 120 & - & - & - & - \\
\hline Martinique & 1 & 66 & 66 & - & - & - & - \\
\hline Corse & - & - & - & - & - & - & - \\
\hline Guadeloupe & - & - & - & - & - & - & - \\
\hline Guyane & - & - & - & - & - & - & - \\
\hline Total & 123 & 33554 & 10240 & 3832 & 17599 & 1632 & 251 \\
\hline
\end{tabular}

Tableau 4- Nombre de diplômés par domaine et par type de diplôme en 2008

\begin{tabular}{|c|c|c|c|c|c|c|c|c|c|c|c|}
\hline \multirow[b]{3}{*}{ Domaines } & \multirow[t]{3}{*}{ Total } & \multicolumn{5}{|c|}{ Diplômes nationaux } & \multicolumn{5}{|c|}{ Diplômes d'établissement } \\
\hline & & \multirow[b]{2}{*}{ Total } & \multicolumn{3}{|c|}{ niveau } & \multirow{2}{*}{$\begin{array}{l}\text { Non inscrits } \\
\text { au RNCP }\end{array}$} & \multirow[b]{2}{*}{ Total } & \multicolumn{3}{|c|}{ niveau } & \multirow{2}{*}{$\begin{array}{c}\text { Non inscrits } \\
\text { au RNCP }\end{array}$} \\
\hline & & & I & II & III & & & I & II & III & \\
\hline Architecture et paysage & 6967 & 6886 & 4761 & 2125 & - & - & 81 & - & - & - & 81 \\
\hline Arts plastiques & 2907 & 2488 & 912 & 148 & - & 1428 & 419 & 271 & - & - & 148 \\
\hline Spectacle vivant & 846 & 325 & - & 45 & 280 & - & 521 & 224 & 34 & 151 & 112 \\
\hline dont Cefedem et CESMD & 253 & 242 & - & - & 242 & - & 11 & - & - & - & 11 \\
\hline et CFMI & 151 & - & - & - & - & - & 151 & - & - & 151 & \\
\hline Patrimoine & 564 & - & - & - & - & - & 564 & 120 & 172 & - & 272 \\
\hline Cinéma et audiovisuel & 46 & - & - & - & - & - & 46 & - & - & - & 46 \\
\hline Total & 11330 & 9699 & 5673 & 2318 & 280 & 1428 & 1631 & 615 & 206 & 151 & 659 \\
\hline
\end{tabular}

\section{Près de 11400 diplômés}

À l'issue de l'année scolaire 2007-2008, 11330 élèves ont été diplômés dans les établissements supérieurs relevant du ministère de la Culture et de la Communication (tableau 4 et encadré, p. 3).

En 2008, 8 élèves sur 10 ont obtenu un diplôme national, dont la moitié de niveau I.

Dans les écoles d'architecture, sur près de 7000 élèves diplômés, plus des deux tiers le sont de niveau I. En arts plastiques, 9 élèves sur 10 ont obtenu un diplôme national.
Dans le domaine du spectacle vivant, la majorité de diplômés $(62 \%)$ a reçu un diplôme d'école. Les diplômes nationaux ne concernent que les diplômes d'enseignement de la musique ou de la danse et le diplôme des métiers d'art. En 2008, 242 élèves ont obtenu un diplôme d'État de musique ou de danse ${ }^{4}$.

En cinéma et audiovisuel, 46 élèves ont été diplômés par la Femis. Le diplôme délivré par cette école - bien que non inscrit au RNCP - est de niveau bac +5 .

4. Il s'agit des DE préparés dans les Cefedem et les CESMD. Le nombre total des DE délivrés en 2008, y compris ceux préparés dans les établissements non relevant du ministère de la Culture et de la Communication, s'élève à 429. 


\section{Les diplômes}

Les formations supérieures artistiques et culturelles relevant du ministère de la Culture et de la Communication aboutissent à deux types de diplômes

- des diplômes d'école délivrés par les établissements sous tutelle du ministère de la Culture et de la Communication;

- des diplômes nationaux délivrés au nom de l'État par le ministère de la Culture et de la Communication ou par le ministère de l'Éducation nationale. Dans le premier cas, il s'agit des diplômes des écoles nationales et territoriales d'art ${ }^{1}$, des diplômes des écoles d'architecture ${ }^{2}$ et des diplômes d'enseignement dans le domaine de la musique et de la danse ${ }^{3}$. Le diplôme des écoles du cirque et de l'école de la marionnette 4 est délivré par le ministère de l'Éducation nationale.

La plupart de ces diplômes sont inscrits au Répertoire national des certifications professionnelles (RNCP). Cette procédure, qui a succédé à l'ancien système d'homologation, consiste à classer, par niveaux et par spécialités, les diplômes délivrés par les organismes publics ou privés. Les diplômes de l'enseignement supérieur sont de niveau I $(\mathrm{bac}+5)$, de niveau II $(\mathrm{bac}+3$ ou 4) ou de niveau III (bac +2$)$.

Certains d'entre eux bénéficient de la reconnaissance aux différents grades du LMD ${ }^{5}$ : depuis 2005, le grade de mastère est conféré au diplôme de restaurateur du patrimoine de l'Institut national du patrimoine et depuis 2006 au diplôme du $2^{\mathrm{e}}$ cycle de l'École du Louvre. En architecture, le diplôme du $1^{\mathrm{er}}$ cycle confère le grade de licence et celui du $2^{\mathrm{e}}$ cycle le grade de mastère. En arts plastiques, la délivrance des premiers DNSEP valant grade de mastère est prévue pour juin 2010.

Dans le domaine du spectacle vivant, des nouveaux diplômes nationaux s'inscrivant dans le cadre du schéma universitaire LMD ont été créés en $2007^{6}$. La formation au DNSP dure 3 ans, elle est assurée dans des établissements habilités, et s'effectue conjointement avec une formation universitaire débouchant sur une licence.

1. Diplôme national d'arts plastiques (DNAP), diplôme national d'arts et techniques (DNAT) et diplôme national supérieur d'expression plastique (DNSEP)

2. Diplôme du $1^{\text {er }}$ cycle : diplôme d'études en architecture et diplôme de $2^{\mathrm{e}}$ cycle : diplôme d'État d'architecte.

3. Diplôme d'État de professeur de musique ou de danse (DE) et certificat d'aptitude aux fonctions de professeur de musique et de danse (CA).

4. Diplôme des métiers d'art (DMA)

5. Licence, mastère, doctorat.

6. Diplômes nationaux supérieurs professionnels (DNSP) de musicien, de danseur, de comédien et d'artiste de cirque.

\section{ANNEXE}

\section{3 écoles relevant du ministère de la Culture et de la Communication*}

\section{Architecture et paysage}

- 20 écoles nationales supérieures

d'architecture

- École de Chaillot

\section{Arts plastiques}

- École nationale supérieure des beauxarts (Ensba)

- École nationale supérieure des arts décoratifs (Ensad)

- École nationale supérieure de création industrielle (Ensci)

- École nationale supérieure de la photographie d'Arles

- Le Fresnoy - Studio national des arts contemporains à Tourcoing

- 6 écoles nationales d'art en région

- 47 écoles territoriales d'art

\section{Spectacle vivant}

- 2 conservatoires nationaux supérieures de musique et de danse

(CNSMD de Paris et de Lyon)

- École de danse de l'Opéra de Paris
- Pôle supérieur d'enseignement artistique Paris - Boulogne-Billancourt

- 11 centres de formation des enseignants de la musique et de danse (Cefedem et CESMD)

- 9 centres de formation de musicien intervenant

- Centre national de danse contemporaine d'Angers

- École supérieure de danse de Cannes Rosella Hightower

- École nationale supérieure de danse de Marseille

- Conservatoire national supérieur d'art dramatique (CNSAD)

- École supérieure d'art dramatique du Théâtre national de Strasbourg

- École d'art dramatique de la Comédie de Saint-Étienne

- École du Théâtre national de Bretagne

-École professionnelle supérieure d'art dramatique région Nord - Pas-de-Calais

- École régionale d'acteurs de Cannes
- École supérieure de théâtre de Bordeaux Aquitaine

- École nationale supérieure d'art dramatique de Montpellier LanguedocRoussillon

- Académie École nationale de théâtre du Limousin

- École supérieure nationale des arts de la marionnette

- École supérieure des arts du cirque

- École nationale des arts du cirque de

Rosny-sous-Bois

- Académie Fratellini

\section{Patrimoine}

- École du Louvre

- Institut national du patrimoine

\section{Cinéma et audiovisuel}

- La Femis École nationale supérieure des métiers de l'image et du son

- École supérieure de l'audiovisuel et du numérique (Ina)

* Il s'agit des établissements qui assurent une formation initiale supérieure.

\section{Sources des données}

Les données sont issues d'une enquête annuelle du ministère de l'Enseignement supérieur et de la Recherche (sous-direction des systèmes d'information et des études statistiques) réalisée en collaboration avec le Département des études, de la prospective et des statistiques du ministère de la Culture et de la Communication. Cette enquête par questionnaire en ligne concerne les formations supérieures dans les domaines des arts plastiques, spectacle vivant, patrimoine, cinéma et audiovisuel dispensées dans les établissements publics et privés quelle que soit leur tutelle.

Les données concernant les écoles nationales supérieures d'architecture proviennent de l'enquête annuelle de la Direction de l'architecture et du patrimoine du ministère de la Culture et de la Communication.

Tous les documents publiés par le DEPs sont téléchargeables sur http://www.culture.gouv.fr/deps

Le DEPS n'assurant pas de diffusion physique de ces documents, nous vous proposons de vous informer régulièrement des parutions par message électronique. Pour ce faire, merci de bien vouloir nous communiquer votre courriel à l'adresse contactdeps.ddai@culture.gouv.fr en indiquant comme sujet du message : «diffusion des collections du Deps ». 